\title{
Analysis and Application of Smart Grid Technology in Monitoring System of Coal Mine Power
}

\author{
Chun Zeng \\ Chongqing Technical and Business Institute, Chongqing, 401520
}

Keywords: Network of mine. Monitoring system. Smart Grid technology. Application

\begin{abstract}
The production of coal mine, grid monitoring system is essential to the security and power equipment. In order to ensure the safety production in coal mine, coal mine power grid monitoring system needs to establish the perfect, so the power transmission and power supply, reasonable control. With the development of technology, smart grid technology also began to constantly applied to grid monitoring system. Therefore, in this paper, through the analysis of the monitoring system of coal mine power grid, thus analysis of smart grid technology in the application of.
\end{abstract}

\section{Introduction}

With the development of economy, as the basis of industries, resources such as coal have always attracted the attention of government. During the feudalistic time, in order to smelt metals and for the purpose of heating, our country has started mining the coal vastly. However, due to the technology limitation and without any mechanical equipment, the efficiency of mining is relatively in low rate. Meanwhile, mining via merely human power, the productivity can satisfy the low market requirements at that time. In contemporary society with the logo of information time, in practical production, the productivity is more efficient with the use of mechanical equipment and electric appliance. However, electric power is consumed with the use of the equipment. Compared with traditional production mode with human, it has increased the cost on equipment but decreased the cost on personnel. Therefore, the current production mode has decreased the production cost after balance. Currently the companies of mining control the cost and improve the efficiency of production via this production mode.

\section{Analysis on Technology of Smart Power Grids}

\section{Background of Smart Power Grids}

Electricity is a hot resource, developed with the development of industry. The discovery of electricity has changed people's live to great extent, especially the appliance, such as electric lights. The electricity has not only changed the traditional life style, but also shifted the working mode. Under this situation, the construction of power supply systems has become the focus in development for a lot of countries. This issue has received widely research from professionals and scholars, and the technical problems are advanced from direct current to alternating current and from low-voltage power supply to extra-high voltage power supply. The productivity of electricity is not without foundation but transfers the power of coal burning and wind power. Therefore it requires the cost to generate electricity. Consequently, when people are consuming electricity they have to pay some money. In order to facilitate the calculation of electricity, the unit of measurement for electricity, electric energy, and the tool of measurement, electricity meter have been developed. According to the results of on-site research, electricity will experience loss during the transmitting procedure due to the resistance of transmitting line. The loss must be taken into account when calculating the cost of electricity. Under this background, it has become the emphasis in research for the researchers to reduce electricity loss in transmitting procedure. Theoretically, to transmit electricity with zero-resistance line will have no loss; however, it is impossible in reality. Therefore the extra-high voltage supply is applied to reduce the loss. This method can't satisfy the advanced requirements as 
the more precise calculation on electricity. Therefore, the smart power grids have been developed in order to control the loss from production to consumption.

\section{Characteristics of Smart Power Grids}

Compared with traditional power grids technology, smart power grids is the new developed smart technology with the development of computer technology. It makes use of advanced sensor and Internet technology, to cascade each nodes involving in electricity, in order to realize the overall control of power grids. For the traditional power grids technology, the main problems are the loss during transmitting and the inaccuracy calculation. At the early stage of power grids construction, the level of grids is relatively lagging behind, with the limitation of technology and infrastructure. Although people have realized the high-voltage supply can reduce the loss of electricity, with poor technology of transformation, the voltage is raised with limitation, resulting in great loss of electricity in transmission. With the development of information technology, the sensors and smart equipment have been developed. In the area of industries automatic control, the smart system can be constructed in use of sensors and other equipment, in order to increase the efficiency of production. In order to improve the efficiency of electricity transmission, the smart technology has been initialized in the construction of power grids. As the results of on-site investigation, it will spend great cost and time in constructing an overall smart grids, because the cover area of grids is rather large and the smart grids is a new technology. Therefore at this stage, the smart gird technology is in application locally and experimentally rather than overall construction. As the influence of special historical factors, development of economy and technology does not experience a long time, and the situation of traditional power girds is relatively poor. However, with the emphasis of the government, and the issue of relevant policies and regulations, the development of power enterprise is in support and developed with deep research of smart power supply grids technology.

\section{Current Situation of Power Grid Monitory System of Coal Mine}

\section{Function of Coal Mine Power Grid Monitory System}

The construction of coal mines, as the main area of coal mining, has been emphasized by government for long period. The development of economy and technology is relatively slow, which is because the block from western developed countries on technologies, and for the reason of the closing development mode of our country in a long period. In fact, we have historical experience in construction of coal mines. During the feudalistic time, our country has started the construction of coal mine for the purpose of heating and smelting. However, without the assistant of mechanical equipment, the efficiency of mining is relatively low. After the industrial age, coal mining has been improved in western developed countries. This is because the utilization of mechanical equipment in the practical production which has improved the production greatly. When it comes into information age, the construction of coal mines has realized the informatization. With the help of electrical devices, the automatic production of coal mining has been realized and the involving of personnel has been greatly reduced. Therefore, the power supply system is very significant to modern coal mines; without electricity supply, the production of coal must be stopped. For this sake, all the countries have emphasized the construction of mining power supply system. In order to optimize the efficiency of electricity utilization, the corresponding power supply monitor system has been established to supervise the electricity consumption of each node in the mines. It is on one hand to control the equipment with large consumption of electricity, and optimize the utilization structure of electricity. On the other hand, for the frequent accidents happened in mines which are mainly caused by the power supply system, the monitor system of power supply in coal mine will enhance the safety in working in coal mines.

\section{Existing Problems in Coal Mine Power Grid Monitory System}

According to the results of on-site survey, in the construction of coal mines, the power grid monitory system has been established as the perspective of safety and production efficiency. With the frequent accidents happened in coal mines, the monitory system has been paid increasing attention to. Via corresponding monitory system, the electricity consumption will be monitored in the coal mines. 
If any part of the electricity consumption is abnormal, the effective actions will be taken on time. Therefore, the monitory system is very important for the routine operation of coal mines. However, in the practical construction of monitory system, the existing problems have influence the operation of monitory system. First is the inspection module of accidents. The current monitory system can only monitor the electricity consumption; when the power supply accident happens, monitory system will provide warning information of the power supply but not the specific type of accident. Secondly, the range of monitor is limited. If the monitor wants to cover specific equipment, it requires a smart chip on the equipment to connect with server via specific web technology. However, the equipment monitored by the system is mostly the traditional type of equipment without sensors. Therefore the problems cannot be feedback on time. It requires the replacement of whole equipment involving in the power grid in order to resolve the problem, which requires a great amount of cost. For enterprises of coal mining, it is impossible to perform such construction without the subsidy from government.

\section{Application Analysis of Smart Grid Technology of Coal Mine Power Grid Monitory System}

\section{Optimize the Structure of Power Utilization to Improve Production Efficiency}

Currently, in the production of coal mine, it mainly relies on the mechanical and electrical equipment, in which the mechanical equipment is for production and the electrical equipment is for control and monitor. After years of development, the high level of mechanization has increased the production efficiency to a great degree. In a sense, the mining of coal with mechanization has reached the maximum. Just like the traditional manpower mining, before the revolution of industries, the efficiency has reached the maximum and it is impossible to improve the production further with manpower. For this time, the construction of coal mine has faced up with the similar problem, which is the development of mechanical equipment has reached the maximum and it is impossible to improve the mining efficiency via the method of mechanization. This is the reason for automatic control technology using in this area. With the use of computers, in many areas of industries, the automatic production has been realized via the control of production in computer. The purpose is to improve production efficiency without change on existing equipment. And it is possible to apply the technology in coal mine power supply monitory system. According to survey, the smart power supply system has been combined with the monitory system in coal mining in some developed western countries. Via the utilization of the technology, the consumption of electricity will be monitored in each production node in mining, so that the power consumption structure will be adjusted according to the monitor results. For the nodes which with less influence on mining efficiency, the consumption can be controlled to reduce the cost of production. Therefore, the use of smart power supply technology can control the cost of production and improve the production efficiency.

\section{Improve the Safety Level of Coal Mine Power Grid}

With the special historical factors, the construction of coal mining, especially in the central plain area, is lagged behind compared with that of western developed countries. As the driven of economic benefits, many small-scale coal mines have been constructed. In the production of these coal mines they have focused on the efficiency of production rather than the safety of production and personnel. Because of the situation, accidents have happened frequently in these mines in recent years. According to surveys on-site, accidents are mainly caused by the open fire in the mine, which is exactly the problem from power supply system. However, the traditional monitory system cannot inspect the safety problems timely; the problem will be improved greatly in using the smart power grid. After installation the corresponding sensors, the system can detect the position and type of the problem, so that the workers can take countermeasures; even the system can provide function of precaution, to detect the malfunction in the power grid before the accidents. Therefore, the application of smart power grid technology is with great significance in improving the safety of power grids in coal mines. 


\section{Conclusion}

In nowadays production in coal mines, it combines with the supply of power closely and large amount of electric equipment. It will improve the production efficiency but bring in the risks. It is because the spark will occur when the voltage is changing; if the open fire occurs in the mines, it will cause safety problems easily. According to the analysis in this paper, in order to improve the safety of power grids in coal mines, there will generally establish a monitory system. However, there exist problems in traditional monitory system, which make the monitory system cannot cover the whole gird. If change to smart power grid technology, not only the power consumption structure and the production efficiency will be optimized, but also the safety will be improved for the power grid in coal mines.

\section{References}

[1]Yang Changdong: Research of Ventilation and Safety Management in High Gas Coal Mining Projects, Values Engineering, 2013(16): 104-105

[2]Liu Lijian, Wang Chunhua and Jia Lihong: Typical Problems and Corresponding Solutions for Usage of Coordinate Measuring Machine, Journal of Hebei Industries and Science, 2006(06): 350-352

[3]Zhang Xiaoming and Li Simin: Cognitive Radio-frequency Spectrum Sensing Algorithm Based on Joint Time Domain and Spatial Domain, Journal of University of Electronic Science and Technology of Guilin, 2010(05): 349-352 